\title{
Histórias de Criança: As Narrativas de Crianças Asmáticas no Brincar
}

\author{
Clándia Maria Teixeira Goulart ${ }^{12}$ \\ Centro Universitário FEEVALE - Novo Hamburgo \\ Tania Mara Sperb ${ }^{3}$ \\ Universidade Federal do Rio Grande do Sul
}

\begin{abstract}
Resumo
Este estudo examinou como crianças com asma constroem significados sobre sua doença e informações que recebem a este respeito. Levou-se a efeito três estudos de caso com crianças participantes de um Programa de Educação em Asma, utilizando uma abordagem cultural que usa as narrativas como um meio de buscar significações. Foram realizadas observações no ambiente hospitalar e entrevistas com mães. Usou-se as narrativas do brincar, já que este permite ampliar o estudo da subjetividade infantil. A análise das narrativas fundamentaram-se no modelo estrutural de Todorov e os resultados evidenciaram que as narrativas no brincar apresentam uma estrutura peculiar, explicada pelas particularidades psíquicas destas crianças. Elementos da cultura estiveram presentes nas narrativas, permitindo a análise de como a criança negocia seus significados pessoais e familiares com os significados da cultura médico-hospitalar. Discutiu-se as implicações do tipo de abordagem educacional que informa as crianças a respeito de sua doença.
\end{abstract}

Palavras-chave: Brincar; asma; narrativa.

Children's Stories: Asthmatic Children's Narratives in Play

\begin{abstract}
This study examined how asthmatic children construct meanings about asthma and the information given to them. A case-study design was used with three subjects involved in a Program of Asthma. A cultural approach which assumes the use of narratives was used to search for children's meanings. Observations in the hospital and interviews with the children's mothers were carried out. Narratives of play were examined to investigate children's subjectivity. These narratives were analysed using Todorov's structural model. Results showed structural alterations in narratives generated in play which may be explained by asthmatic children's psychological particularities. Culture features were strongly present allowing for the analysis of how children negotiate their personal and familiar meanings with the meanings of the medical culture in which they are embedded. The educational approach which informs children about their diseases is discussed.

Keywords: Play, asthma; narrative.
\end{abstract}

Apesar do fluxo constante do desenvolvimento infantil, alguns fatores podem influenciar nesse processo e fazer com que certas crianças precisem lidar com situações diferenciadas em suas vidas. A doença crônica é um exemplo disso. A criança com doença crônica precisa de acompanhamento médico constante, convive com o risco de vida e com as restrições relativas ao seu quadro clínico. Desta maneira, a doença adiciona uma dimensão diferente à sua vivência infantil, muitas vezes, expondo-a a internações que a retiram

\footnotetext{
${ }^{1}$ Este trabalho é uma síntese da dissertação de mestrado apresentada no Curso de Pós-Graduação em Psicologia da Universidade Federal do Rio Grande do Sul, sob orientação da $\operatorname{Dr}^{\mathrm{a}}$. Tania Mara Sperb. Este estudo contou com apoio financeiro do CNPq e CAPES.

${ }^{2}$ Endereço para correspondência: Av Ipiranga, 853/404, 90160 092, Porto Alegre, RS. Fone/fax: 32338531.E-mail: cgoulart@portoweb.com.br; sperbt@terra.com.br

${ }^{3}$ As autoras agradecem à toda equipe do Programa de Educação em Asma do Hospital de Clínicas, em especial à Dra. Vera Guirland Vieira, pela disponibilidade com que nos acolheram para a realização desta pesquisa.
}

do seu ambiente (casa, escola, amigos). Apesar de todos estes fatores, esta criança continua a se desenvolver e precisa ter recursos, tanto sociais quanto psíquicos, para lidar com isso.

Os indivíduos com doença crônica deparam-se com o fato de que, pela natureza de sua doença, eles podem ser tratados, mas não curados. Em função disso, estes pacientes, progressivamente, adquirem a noção de que precisam cuidar de si mesmos para controlar os aspectos relativos à sua doença. Normalmente, no entanto, a atenção recai sobre os aspectos físicos da doença crônica, sendo que só recentemente os aspectos psicológicos e sociais começaram a ser enfatizados (Shute \& Paton, 1990).

A asma, por exemplo, é uma doença crônica em que os fatores psíquicos - tanto desencadeantes como decorrentes da enfermidade - são extensamente descritos na literatura. Abordagens atuais, a respeito do tratamento de crianças com asma, têm enfocado a importância de Programas de Educação sobre Asma para pacientes e familiares com o 
objetivo de auxiliar pais e crianças a controlar melhor sua doença, melhorando sua qualidade de vida (Howel, Flaim \& Lum Lung, 1992). O enfoque destes programas tem sido o de informar. No entanto, sabe-se que é necessário fornecer instrumentos para que a criança com doença crônica possa expressar seus sentimentos, falar sobre suas experiências e dúvidas.

No Hospital de Clínicas de Porto Alegre, vem sendo desenvolvido um trabalho com crianças asmáticas que tem como objetivo principal proporcionar a estas crianças um atendimento multidisciplinar, em nível ambulatorial. $\mathrm{O}$ trabalho tem sido desenvolvido a partir de atividades para as crianças e seus pais. Uma dimensão importante é entender as significações que as crianças deste grupo constroem a respeito da asma, do fato de estarem doentes, da própria participação neste grupo e de como a cultura médicohospitalar permeia esta construção. Para isso, pode-se utilizar como modelo a concepção de Bruner (1990/1997) a respeito de narrativas. Nesta visão, as narrativas são construídas para dar sentido à experiência e organizá-la. A narrativa será criada sempre que algo não for como deveria ser na vida de um indivíduo e que este precise ressignificar sua experiência. Não seria surpreendente, portanto, que as crianças asmáticas que participam de grupos específicos sobre a sua doença dentro de um hospital construíssem narrativas para dar significado àquilo que está acontecendo com elas.

$\mathrm{O}$ ambiente hospitalar pode ser um recurso para que a criança tenha informações sobre as especificidades de sua patologia, os cuidados que precisa ter e, também, para que possa resgatar seus aspectos sadios e significar a doença dentro do contexto mais amplo de sua vida. Crianças com asma, muitas vezes, vivenciam restrições em seu nível de atividade que são desnecessárias. Um maior conhecimento a respeito da doença permitiria, por exemplo, que a criança participasse de esportes e atividades, tivesse menos faltas à escola em função da asma, dormisse melhor à noite e evitasse incômodos decorrentes de seus sintomas e dos efeitos colaterais da medicação.

Alguns autores (Howel \& cols., 1992; Snadden \& Brown, 1992) enfatizam a importância de estudos que examinem o impacto dos programas de atendimento a pacientes com asma, já que algumas pesquisas têm mostrado que, embora programas educacionais aumentem o conhecimento e o entendimento dos pacientes sobre sua patologia, isto não afeta os comportamentos de autocuidado ou a morbidade.

Segundo Johnson (1985, citado em Shute \& Paton, 1990), tais pacientes devem ser vistos dentro de um contexto, o qual compreende as pessoas que são significativas para essa criança. O sistema de crenças da família irá interferir na habilidade de lidar com a informação que é passada sobre a doença, o que faz com que seja importante também investigar as suas concepções. Para alguns autores (Howel \& cols., 1992), se os familiares acreditam, por exemplo, que a asma irá passar com o tempo, ou negam a doença, eles terão dificuldade para tomar medidas preventivas e medicações profiláticas. Se consideram, por outro lado, que a responsabilidade sobre os cuidados em uma crise é apenas dos médicos e que eles são incapazes de lidar com a situação, podem não realizar as intervenções apropriadas.

Os efeitos desse tipo de informação sobre a criança e a maneira como ela significa este conhecimento que lhe está sendo passado, entretanto, ainda não foram pesquisados. $\mathrm{Na}$ visão de Snadden e Brown (1992), "os profissionais da área da saúde necessitam conhecer os efeitos da doença, tecnologia e medicação, não somente em termos clínicos, mas também sobre a vida de seus pacientes" (p. 1357). Para isso, deve-se voltar o olhar para as crenças, os medos, as atitudes e o entendimento que estes pacientes têm a respeito de sua doença.

Segundo Oliveira (1993), "há uma dicotomia profunda entre o que a criança percebe como enfermidade, hospitalização e cuidado e o que a Medicina oferece como saúde, ato médico e tratamento" (p. 329). Desta forma, o impacto psicológico e a significação que a criança e sua família irão construir a partir de um imperativo, como por exemplo, doença sem cura, é um ponto a ser discutido.

Além disto, programas dirigidos às crianças devem adequar-se ao estágio do desenvolvimento e habilidades cognitivas destes pacientes. É importante ter-se em mente o nível de responsabilidade que esta criança pode assumir e o tipo de informação que ela pode entender ( Howel \& cols., 1992; Quinn, 1988). Tendo em vista que os teóricos que trabalham com fenômenos psicossomáticos apontam um tipo específico de pensamento, denominado por Marty (1990/1993) de pensamento operatório, em pessoas que apresentam doenças psicossomáticas, que pode levar a uma aderência muito grande às informações que the são dadas, deve-se ter cuidado quanto à maneira que as informações são fornecidas. Além disso, um monitoramento de como as crianças significam estes conhecimentos é fundamental.

Quando se trabalha com a perspectiva da própria criança em relação à sua doença, existem diferentes modos de examinar esta questão. Neste estudo, optou-se por uma metodologia que amplie as possibilidades de análise sobre o entendimento que a criança tem da doença ou como negocia o que ela aprende de informação com o tipo de raciocínio que tem neste momento. $\mathrm{O}$ estudo das narrativas criadas pelas crianças permite o acesso às suas construções a respeito do que se passa em suas vidas. No intuito de não restringir-se à palavra, que na infância nem sempre é eficaz 
para a expressão de sentimentos e afetos, uma alternativa para compreender-se o ponto de vista infantil é trabalhar a partir das narrativas que surgem no brincar. A análise das narrativas presentes no brincar para pesquisar o desenvolvimento de crianças pequenas é uma via utilizada por muitos teóricos (Benson, 1993; Buchsbaum \& Emde, 1990; Vieira \& Sperb, 1998). Embora seja possível localizar estudos (Buchsbaum, Toth, Clyman \& Cicchetti, 1994; Hemphill, Feldman, Camp \& Griffin, 1994) que examinam as narrativas orais de crianças que passam por algum tipo de situação difícil em suas vidas, não foram encontradas pesquisas sobre as narrativas presentes no brincar, especificamente de crianças com doença crônica. Assim, neste estudo, o interesse está relacionado às possíveis peculiaridades existentes nas narrativas presentes no brincar de crianças asmáticas.

Para Bruner (1990/1997), as pessoas organizam sua experiência e seu conhecimento sobre o mundo a partir de um sistema de crenças que é a "psicologia popular". O seu princípio organizador, no entanto, não é conceitual, mas narrativo. Justifica, desta forma, o estudo das narrativas, uma vez que estas são construídas para dar sentido à experiência e organizá-la. A narrativa será criada sempre que algo "não for como deveria ser" (p. 44) na vida de um indivíduo e que este precise ressignificar sua experiência. É no encontro entre os estados percebidos do mundo e os desejos da pessoa que surge a dramaticidade nas narrativas.

A narrativa apresenta na seqüencialidade a sua principal propriedade. "Uma narrativa é composta por uma seqüência singular de eventos, estados mentais, ocorrências envolvendo seres humanos como personagens ou atores" (Bruner, 1990/1997, p. 46). Cada um destes constituintes irá adquirindo uma significação, a partir do lugar que ocupa dentro do enredo da narrativa, de sua seqüência.

Uma característica crucial da narrativa é que ela procura estabelecer ligações entre o excepcional e o comum. Tal fato nos leva a considerar a hipótese de que as crianças que se encontram frente à situação de uma doença crônica possam utilizar-se de narrativas para tentar explicar o que acontece com elas. A experiência da doença também pode mudar a maneira como os indivíduos pensam a si mesmos, seu presente, seu futuro, bem como o passado. $\mathrm{Na}$ narrativa pessoal da doença, freqüentemente, o que está sendo contado não pode ser visto simplesmente como a história de uma doença, mas mais como a história de uma vida alterada pela doença (Garro, 1994).

Parte-se do pressuposto, portanto, de que o entendimento a respeito de como as crianças constroem significados sobre sua doença não deve centrar-se apenas em aspectos individuais, mas deve levar em conta os diferentes contextos culturais em que elas estão situadas; em particular, neste estudo, as culturas hospitalar e familiar. O referencial que as crianças e suas familias têm para construir um saber a respeito da asma deve ser entendido a partir da concepção de que a cultura regula esta construção. Em função disto, utilizou-se as observações do ambiente hospitalar e entrevistas com as mães, que forneceram subsídios para melhor situar tais contextos. Isso torna possível o estudo das significações individuais inseridas em uma forma pública e compartilhada. A doença irá adquirir significados diferentes, dependendo do tipo de intervenção que se pode ter sobre ela e da maneira como a cultura lida com isso.

Não é apenas através da fala que a criança pode construir narrativas. A função comunicar já está estabelecida na criança mesmo antes do domínio da linguagem formal e de sua expressão lingüística. Na visão de Bruner (1990/1997), "uma apreensão protolingüística da psicologia popular já está presente como uma característica da práxis, antes mesmo que a criança seja capaz de expressar ou compreender as mesmas questões através da linguagem" (p. 70). Autores como Barthes (1977) e Goodman (1981) ampliam o conceito de narrativa para além da linguagem oral ou escrita. Barthes (1977) considera que as narrativas sobre o mundo são diversas e podem ter como suporte a linguagem articulada, oral ou escrita; a imagem, fixa ou móvel; os gestos e a mistura ordenada de todos estes aspectos.

Ao examinar a brincadeira simbólica em crianças, numa situação de psicodiagnóstico, Vieira (1997) considerou que este organiza-se em torno de alguma forma narrativa. Utilizou o conceito de narrativa de Todorov (1973) e recorreu a estudos sobre imagem, uma vez que a brincadeira simbólica muitas vezes organiza-se como imagem. Nos três casos estudados, verificou que as crianças podem construir uma narrativa de diferentes formas: a narrativa pode apoiarse tanto na linguagem como na imagem, sendo que os elementos vão sendo acrescentados à história tanto pela via do brincar quanto por verbalizações. Neste caso, a linguagem "se faz presente na forma da própria estrutura narrativa do brincar" (Vieira \& Sperb, 1998, p. 243).

O modelo estruturalista de narrativa, proposto por Todorov $(1971,1973)$, parece ser o mais adequado para o estudo das narrativas construídas pelas crianças na brincadeira simbólica. Segundo Vieira e Sperb (1998), tal esquema adequa-se ao estudo das narrativas presentes no brincar simbólico pois, em função de seu caráter estruturalista, prescinde de elementos lingǘsticos, tais como conetivos causais, essenciais para outros modelos que trabalham diretamente com a linguagem oral ou escrita.

Na perspectiva de Todorov (1971, 1973), toda seqüência narrativa trataria da passagem de um estado de equilíbrio a outro, semelhante, mas nunca idêntico ao primeiro: 
A narrativa ideal começa por uma situação estável que uma força qualquer vem perturbar. Daí resulta um estado de desequilíbrio; por ação de uma força dirigida em sentido inverso, o equilíbrio é restabelecido ... Há, por conseguinte, dois tipos de episódio na narrativa: os que descrevem um estado (de equilíbrio ou de desequilíbrio) e os que descrevem a passagem de um estado a outro. (Todorov, 1971, p. 124)

Adam (1985) realiza uma nova leitura do modelo proposto por Todorov e acentua a importância da análise do processo que se dá na passagem e transformação do estado inicial (Pn1) em um estado final (Pn5). As proposições intermediárias (Pn2 - Pn3 - Pn4) são importantes no sentido de que asseguram tal transformação. Este autor não considera, entretanto, que um estado inicial seja, necessariamente, um estado de equilíbrio, sendo possível que uma narrativa já inicie a partir de um estado de desequilíbrio. Isso amplia as possibilidades de utilização do modelo proposto por Todorov. Neste estudo, busca-se verificar como as crianças estruturam suas narrativas e como organizam as proposições intermediárias justamente nessa passagem de um estado inicial a um estado final.

Sendo assim, considera-se que as narrativas infantis podem ser estudadas não só a partir de construções orais e escritas, mas também a partir da brincadeira simbólica. Utiliza-se as narrativas do brincar, uma vez que pedir às crianças que contassem sobre a história de suas vidas poderia trazer algumas limitações ao ampliar o grau de complexidade da tarefa. Nas palavras de Bruner (1987), "a história de nossa própria vida é, certamente, uma narrativa privilegiada mas problemática, no sentido de que esta é reflexiva: o narrador e a figura central na narrativa são os mesmos" (p. 13). Isto toma uma dimensão maior nas crianças que, em processo de desenvolvimento, não se encontram amplamente capazes de transpor sua história e seus sentimentos em representações lingüísticas.

O uso do brincar, neste sentido, traz uma série de vantagens. A literatura sobre crianças em diferentes contextos exemplifica a importância do brincar para o desenvolvimento infantil (De Conti \& Sperb, 2001; Mello, Faschel \& Sperb, 1997; Mello, Goulart, Ew \& Sperb, 1999; Vieira \& Sperb, 1998). Aquilo que a criança, muitas vezes, não verbaliza a respeito de suas emoções, alegrias, conflitos, enfim, pode ser expressado pelo brincar. O estudo das narrativas destas crianças pode fornecer elementos para pensar-se como a doença se reflete na vida destas crianças como um todo.

Com base no que se conhece a partir da revisão da literatura, observa-se a necessidade de desenvolver mais estudos a respeito do efeito de programas de suporte social para crianças com asma (Howel \& cols., 1992). Em vista disso, este estudo desenvolve-se no contexto em que as crianças e suas famílias participam de programas específicos para crianças com asma. Uma vez que tais programas são desenvolvidos na instituição hospitalar, considera-se que a cultura médico-hospitalar torna-se parte da vida desta criança e como tal permeia a maneira como a criança significa sua doença.

O objetivo deste estudo, portanto, foi examinar a perspectiva das crianças com diagnóstico de asma e as possíveis narrativas presentes em suas brincadeiras simbólicas. A partir de tais narrativas, tornou-se possível identificar e analisar as significações que as crianças constroem a respeito de sua doença e das informações que recebem a respeito dela. Uma vez que as narrativas são construídas tendo como pano de fundo elementos da cultura, analisou-se como a criança negocia seus significados pessoais e familiares com os significados advindos da cultura médico-hospitalar, da qual passaram a fazer parte. Com o objetivo de verificar como se constroem os significados familiares foram realizadas entrevistas com as mães das crianças.

\section{Método}

\section{Participantes}

Participaram deste estudo 2 meninos e 1 menina, que serão chamados de Vítor, Rafael e Larissa, respectivamente, com 8 anos e 2 meses, 8 anos e 3 meses e 8 anos e 6 meses. Todos freqüentam o Programa de Atendimento à Criança Asmática no Hospital de Clínicas de Porto Alegre e apresentam o diagnóstico de asma de intensidade moderada ou severa. As crianças foram escolhidas dentro de uma mesma faixa etária, no sentido de minimizar as diferenças decorrentes de fases distintas do desenvolvimento.

\section{Instrumentos e Material}

Foram realizadas observações das reuniões do grupo que participa do Programa de Atendimento à Criança Asmática e das reuniões de equipe dos profissionais que trabalham com estas crianças. Foram feitas entrevistas abertas com as mães das crianças, pedindo-lhes para que contassem a história da vida de seus filhos e sessões de brincadeira foram realizadas em uma sala dentro do próprio hospital, tendo como pano de fundo uma casinha de madeira que é utilizada nas aulas do Programa. Os pais e as crianças que concordaram em participar do estudo assinaram um termo de consentimento informado.

\section{Delineamento e Procedimentos}

Utilizou-se o delineamento de múltiplos casos (Yin, 2001), sendo cada caso uma criança. A principal unidade de análise é a forma como as crianças constroem significações a respeito de sua doença. A subunidade corresponde às 
narrativas no brincar, desenvolvidas dentro do contexto hospitalar.

Para a realização deste estudo a pesquisadora participou de reuniões técnicas que visavam o planejamento das atividades realizadas nos grupos. Além disso, foi feito um acompanhamento de todas as reuniões dos grupos, envolvendo o trabalho com as crianças e seus pais, através da inserção nos grupos de crianças, observando e interagindo com estas durante as atividades específicas realizadas com os grupos. A participação nestes encontros teve o intuito de conhecer o contexto em que esse programa se desenvolve. A partir disso, as crianças e seus pais foram convidados a participar, sendo que no caso das três crianças deste estudo eram somente as mães que participavam das atividades do grupo. Os participantes do grupo, tanto as crianças como os familiares, foram informados a respeito dos procedimentos que seriam realizados neste estudo, através da descrição dos objetivos e da justificativa do estudo.

As mães das crianças foram entrevistadas para que se pudesse ter um conhecimento mais abrangente a respeito destes sujeitos, bem como da cultura em que estão inseridos. Sessões de brincadeira simbólica foram realizadas individualmente, filmadas e posteriormente transcritas, visando-se a análise das narrativas. As filmagens foram feitas em uma sala dentro do próprio hospital, tendo como pano de fundo uma casinha de madeira que é utilizada nas aulas do Programa. Os brinquedos utilizados incluíram famílias de bonecos, animais, carrinhos, tijolinhos de madeira, massinha de modelar, bem como sucata de material hospitalar. A pesquisadora, que já conhecia cada criança por participar das reuniões do Programa, mostrava os objetos de brincar que ficavam à disposição da criança e lhe dizia que poderia escolher os materiais a serem utilizados para brincar. A partir disto as crianças brincavam livremente, sendo que a pesquisadora interagia quando solicitada ou fazendo perguntas sobre a brincadeira.

\section{Resultados e Discussão}

Foram analisadas as narrativas construídas pelas crianças na atividade de brincar e o discurso das mães a respeito de seus filhos. O processo de análise, inicialmente, verificou se a atividade de brincar realizada pelas crianças apresentava uma estrutura narrativa, utilizando o modelo de Todorov (1973). Analisou-se narrativas dentro da perspectiva cultural proposta por Bruner (1990/1997), isto é, de que a narrativa vem dar conta da experiência, dando-lhe uma significação.

Apresenta-se neste artigo os resultados surgidos a partir de um recorte efetuado pela pesquisadora no sentido de evidenciar o tema das narrativas no brincar nestas crianças com quadro de doença crônica e os reflexos da cultura e do programa de educação em asma nestas narrativas.

\section{O que as Crianças Contam...}

A análise dos episódios criados pelas três crianças que participaram deste estudo mostrou que, como propôs Vieira (1997), o brincar simbólico organiza-se como uma narrativa e, portanto, pode ser examinado como tal. Além disso, verificou-se que a cultura hospitalar está presente e influencia a construção das narrativas das crianças no brincar, especialmente quando se examina os momentos em que há uma perturbação no equilíbrio da história.

Um exemplo disso é a natureza da força perturbadora, da qual fala Todorov (1973), que vem abalar um equilíbrio estável da história criada pelas crianças e que nestes casos estudados, muitas vezes esteve relacionada com a asma. Vejamos, a seguir, um exemplo em que a força perturbadora aparece somente para os personagens que têm asma:

L-Daí a babá foi lá correndo, tirou e eles ficaram chorando: buá-buá. daí ela (mostra uma boneca) ficou pintando, mas ela não tinha asma, ela ficou pintando ... só que essa aqui (pega a boneca Larissa que até agora ainda estava deitada ao lado da cama da mãe) ela tinha asma...daí ela começou atichin, atchin, atchin, atchin, atchin, atchin (Menina Larissa sai espirrando pelo quarto e desce para o andar debaixo e vai até a empregada) Daí a empregada perguntou: o que é que houve? Daí ela: ai, é que aquele quarto tava com um cheiro muito forte. atichin, atchin, atchin, atchin. Daí ela ficou lá na sala junto com os bebês.

Vimos, acima, que só o personagem que não tinha asma pôde continuar sua atividade, no caso a pintura, a personagem com asma teve que ficar junto aos bebês. Em outro momento, a figura do ácaro também foi utilizada como um complicador que veio perturbar o equilíbrio da cena:

Daí...a mamãe viu que, quando acordou, tava com um cheiro muito ruim no quarto (coloca a lata de brinquedos de lado e pega a mamãe, levanta-a da cama e vai em direção ao ácaros) Iec (faz uma cara de nojo) tava com um cheiro de ácaro (mãe olha os ácaros, se abaixa e olha bem de perto) daí ela olhou pro chão, bem...olhou assim, e achou um montão de ácaro. oh, Meu Deus, meu Deus, (o pai vem correndo, chuta um ácaro, escorrega no chão e cai) iah, puf, iah, puf (a boneca de lenço vem atrás) o que houve, o que houve? deixa eu ver iah, puf (também chuta, escorrega e cai) É uma ácaro, é um ácaro, tire ele imediatamente daqui ... Vamos limpar ... Um ácaro, Meu Deus! esta casa está cheia de ácaros. 
Nesta seqüência criada por Rafael, a utilização da limpeza, que é ensinada nas aulas do Programa como uma maneira de controlar a doença, apareceu como aquilo que poderia restabelecer o equilíbrio.

Os personagens e suas ações, portanto, são caracterizados a partir do universo simbólico da cultura em que estas crianças estão inseridas. Mesmo que as narrativas contenham inovações que as descolam do ato em si, “... a composição da intriga está enraizada numa pré-compreensão do mundo e da ação: de suas estruturas inteligíveis, de suas fontes simbólicas ...” (Ricouer, 1983/1994, p. 88). Porém, o que chama atenção nestas crianças, é a maneira como utilizam os mediadores da cultura (tanto cultura médico-hospitalar como cultura familiar). Não há muitos espaços para inovações e transgressões em suas narrativas. Mesmo que o processo de criação de obras imaginativas não seja original do autor, consiste em uma reformulação de um material já existente, o que aponta para a independência do autor, que pode ser verificada pela própria escolha dos elementos e pelas alterações realizadas. É precisamente nestas alterações possíveis que as narrativas das crianças deste estudo apresentam-se restritas.

Bruner (1990/1997) chama atenção para o fato de que a dramaticidade da narrativa estará diretamente relacionada a uma interlocução entre os estados percebidos do mundo e os desejos da pessoa que a cria. Como visto anteriormente, a maneira como as crianças asmáticas, neste estudo, estruturam-se como sujeitos de seu desejo produz um tipo de produção simbólica muito peculiar, que se aproxima do conceito de pensamento operatório, descrito por Marty (1990/1993). Neste sentido, a estrutura de suas narrativas apresentou alterações que podem ser relacionadas à vivência da doença como um todo e às questões subjetivas das crianças.

Nos três casos estudados, encontramos uma variação no que se poderia chamar de proposições internas da narrativa, ou seja, o que aconteceu foi que, a partir de uma proposição estável inicial (Pn1), cada uma das crianças estruturou suas narrativas de forma distinta. Ou seja, a estrutura não se apresentou de forma linear ((Pn1)-(Pn2)(Pn3)-(Pn4)-(Pn5)), mas variou dependendo do sujeito que a construiu. No caso de Larissa, os elementos perturbadores do equilíbrio e a força no sentido de restabelecê-lo alternavam-se sem que um estado de equilíbrio, ou um final para a história fosse proposto ((Pn1)-(Pn2)-(Pn3)-(Pn4)(Pn2)-(Pn3)-(Pn4)...(Pn5)), ou seja, havia uma circularidade entre $(P n 2),(P n 3)$ e $(P n 4)$. Nas narrativas de Rafael, o que ocorreu foi um dos momentos de desequilíbrio, sem que nenhuma força pudesse restabelecê-lo ((Pn1)-(Pn2)-(Pn3)(Pn2)-(Pn3)-...(Pn5). Uma referência especular, em que a morte de um causava a morte, em cadeia, de todos os outros personagens tornava sua narrativa caótica.

P- Como é que acabou?

R- Eles caíram todos. Muito obrigado, muito obrigado (faz uma reverência)

P- Eles caíram e...

R- daí eu falei...todo mundo morreu e acabou a história

P- Todo mundo morreu e acabou a história?

Em função das particularidades de suas histórias de vida e de suas possibilidades de elaborar as questões que lhes são próprias, cada uma das crianças faz uma marca pessoal em suas narrativas. Se a dificuldade de Larissa era dar um final para sua história, no caso de Rafael a narrativa termina com a morte de seus personagens. Em ambos os casos, o que motiva essa alteração estrutural pode ser associado com uma questão psíquica. Já no brincar de Vítor, o que se manteve como uma característica foi a ausência de forças perturbadoras bem delimitadas, o que tornou suas narrativas pouco dinâmicas e também sem um final. Por que deter-se, no entanto, nessa ausência de final? Algo intriga nesta característica de suas narrativas e lembra o que diz Ricouer $(1983 / 1994)$ a respeito da função do final para uma história:

Seguir uma história é avançar no meio de contingências e de peripécias sob a conduta de uma espera que encontra sua realização na conclusão ... Ela (conclusão) dá à história um "ponto final", o qual, por sua vez, fornece o ponto de vista do qual a história pode ser percebida como formando um todo. Compreender uma história é compreender como e por que os episódios sucessivos conduziram a essa conclusão, a qual, longe de ser previsível, deve ser finalmente aceitável, como congruente com os episódios reunidos. (p. 105)

A maneira como Vítor, Larissa e Rafael posicionamse frente ao final de suas histórias leva a pensar sobre a história que vivem em relação à asma. Nesta história talvez não exista a possibilidade de um final feliz, já que a cura não é uma alternativa viável, seguindo o que a cultura médica ensina. A morte, também, surge como um final possível, já que é uma doença que lhes ameaça a vida. Sendo assim, o desequilíbrio ainda sobrepõe-se a outras possibilidades. Talvez essas crianças precisem brincar muito ainda, criar muitas narrativas e, assim, construir um final singular para as suas histórias.

Segundo Todorov (1973), uma seqüência narrativa comporta um número mínimo de proposições, mas outras proposições podem estar envolvidas, sem que isso torne possível identificar duas seqüências autônomas, ou seja, todas as proposições entram em um esquema de base. Esta 
característica também foi verificada nas narrativas das crianças, mesmo que o ordenamento das proposições internas fosse variável. Inseridas em uma seqüência narrativa maior, pequenas seqüências eram criadas, o que tornava a narrativa mais complexa. A ausência desta complexidade no caso de Vítor, por exemplo, reforça a idéia de que sua produção simbólica é mais pobre do que a dos outros dois casos.

Alguns exemplos evidenciam esta idéia. A ocorrência de um evento externo à seqüência que Larissa vinha desenvolvendo provoca um novo rumo à história, que só se torna mais claro no decorrer da história. Após cair um quadrinho da casinha de bonecas, o evento é incorporado a narrativa:

L-Daí caiu um quadro, bah dois quadros caíram junto! PDois quadros caíram! L-É. (o quadro do quarto dos pais também caíra, Larissa os recoloca na parede) Daí era a filhinha que pintava esses quadros ... L- Essa daqui vai ser a ... Larissa, é ... o meu nome! ...

Esse evento externo servirá como pano de fundo para Larissa falar sobre as limitações que são impostas a uma criança que tem asma.

Já no caso de Vítor, há uma cena em que este arruma cuidadosamente o bebê no colo da boneca, mas ele cai várias vezes. Vítor não incorpora esse evento à narrativa. Mesmo preocupando-se em restabelecer o equilíbrio causado quando o bebê cai, não o incorpora ao contexto do brincar. A forma distinta como essas duas crianças utilizaram um evento externo à narrativa que elas constroem, seja incorporando-o à narrativa ou tentando desfazê-lo, pode sugerir que tipo de recursos estas crianças têm para lidar com o que lhes acontece: inserir tais eventos no brincar e tentar elaborá-los ou mantê-los fora desse circuito, limitandose a uma pura repetição sem possibilidade de elaboração.

\section{Histórias de Mães ....}

O impacto que a asma causa em diferentes aspectos da vida destas crianças fica evidente no decorrer do estudo dos três casos. A doença constitui-se como a referência principal das mães ao contarem sobre seus filhos. Isso é mais forte no caso de Vítor, um menino em que o histórico de suas patologias confunde-se com sua própria história. De forma menos evidente, mas de maneira igualmente significativa, as mães de Rafael e Larissa narram a vida de seus filhos a partir de suas crises. Não se pode perder de vista, entretanto, o fato de que as entrevistas foram feitas por uma pesquisadora que estava inserida na cultura hospitalar. Para essas mães, a pesquisadora estava relacionada a este saber médico, embora soubessem de sua formação como psicóloga. A questão de que o contexto em que estas histórias foram contadas influencia nos seus conteúdos é pertinente, mas não parece invalidar essa análise. Tomemos como exemplo uma parte da entrevista com a mãe de Vítor em que se pergunta a ela: "Bom, e além da doença..." e ela responde: "Ah, além das doenças ele é uma criança muito saudável". Como uma face da mesma moeda, a categoria saúde, ou seja, uma referência muito forte ao corpo surge como possibilidade de descrever o filho.

Importante também é que, em todos os casos, foram identificados problemas escolares. Todas as três crianças têm oito anos de idade e, portanto, a escola tem um papel fundamental em suas vidas. Segundo as mães, os problemas são causados pelo grande número de faltas em função das crises; além disso, porém, podemos levantar a hipótese de que a pobreza simbólica que pôde ser caracterizada a partir do brincar dessas crianças, pode estar relacionada, também, ao baixo rendimento escolar.

Diversos estudos (Bennet, 1994; Padur \& cols., 1995) têm mostrado que crianças com asma têm mais risco de apresentar sintomas depressivos, baixo auto-conceito e angústia do que crianças com outras doenças crônicas (câncer, fibrose cística, diabetes). Muito embora o objetivo deste estudo não seja examinar problemas afetivos que podem estar associados à asma, foi possível identificar a presença de alguns desses sintomas nestas crianças. No caso de Larissa, as inúmeras referências ao sono que advém depois das crises de asma podem ser um indicativo da dificuldade que está tendo em lidar com suas crises, o que a coloca em uma posição depressiva, evidenciada pelo sono.

Outro aspecto importante é a preocupação recorrente com a morte. A mãe de Larissa conta que a filha preocupase constantemente com a morte e que, ao ficar doente, pergunta se vai morrer. No caso de Rafael, a problemática da morte vem associada a uma pergunta pela morte de seu próprio pai. Em suas narrativas, contudo, os ácaros (significante associado à asma) são os responsáveis pela morte. Isso parece ser um indicador de que há aí um questionamento a respeito de sua própria doença e da possibilidade da morte em função dela. Mesmo que estas duas crianças tenham experiências pessoais ligadas à morte de alguém próximo, o pai, o avô ou uma amiguinha, o fato de terem uma doença que lhes ameaça a vida confere uma outra dimensão a estas vivências. O significante morte também pôde ser encontrado em Vítor, que tem sua vida ameaçada constantemente por severas crises de asma. Esse assunto merece atenção nas intervenções que são levadas a efeito com estas crianças. $\mathrm{O}$ hospital, por exemplo, foi freqüentemente situado, em suas narrativas, não como o lugar em que as pessoas são curadas, mas como o lugar em que as pessoas vão antes de morrer. Isso mostra que estas crianças mantêm inseguranças a 
respeito do que pode ser feito em relação à sua doença. Paralelo a isso, pode-se pensar na questão da cura e lembrar que no Programa é enfatizado o fato de que asma não tem cura. As mães referem em suas entrevistas experiências de pessoas que foram curadas e buscam uma legitimação disso no discurso médico. Larissa vê como um final possível para a sua história a cura do bebê que tem asma. Para além da verdade médica, portanto, fica como questão os efeitos desse diagnóstico para a constituição psíquica destas crianças.

Diversas hipóteses foram formuladas pelas mães a respeito da causa das enfermidades de seus filhos. Estas causas alternavam-se entre causas físicas e emocionais. Vejamos o que as mães dizem a este respeito: "E a primeira crise de bronquite que ela teve, ela tinha 1 ano e 4 meses. Eu morava em casa, daí quando ela tinha 1 ano e 2 meses eu me mudei para um apartamento ... É que o apartamento que eu morava era muito úmido, muita umidade, muito cheiro de mofo ... a Larissa é assim muito, como é que eu vou te dizer assim ... eu notei que ela não pode ficar ansiosa, se ela ficar ansiosa ela tem crise".... eu estava bem tranqüila que a causa era o clima ... e ela teria me dito que isto era fundo emocional, que ele poderia ter se estressado com alguma coisa. Vê-se, portanto, que há uma alternância entre os possíveis fatores que desencadeiam as crises, isso podendo ser encontrado, também, nos episódios de brincar. Larissa, em sua narrativa, conta sobre um bebê que tem crise ao ficar sozinho com o pai, ou seja, não há nada no ambiente que apareça associado. Já em outra seqüência, são as tintas, os ácaros, ou a falta dos remédios que causam as crises.

É interessante lembrar, no entanto, que para a mãe de Vítor os componentes emocionais não estão associados às crises do filho. Mesmo que construa uma hipótese de que as crises da outra filha acontecem quando ela está nervosa, não supõe que em Vítor isto possa acontecer. Os desencadeantes das crises de Vítor são relacionados a mudanças no tempo, à sua alergia aos cães e gatos da casa ou aos exercícios físicos. Para a mãe de Vítor, o que fala é o corpo, sem muitos espaços para a dimensão psíquica. Isso é um indicador de que as crenças em relação à doença não são construídas apenas em função do conhecimento popular que faz parte da cultura, mas são moduladas pela posição subjetiva daquele que formula uma ou outra hipótese.

De modo geral, portanto, os fatores desencadeantes que aparecem neste estudo refletem as investigações da comunidade científica ao redor dos fatores psíquicos envolvidos na deflagração das crises, no agravamento das mesmas e em casos em que não são encontrados fatores alergênicos definidos. Mesmo que a medicina avance e insista no caráter orgânico da asma, como foi salientado por
Kreisler, Fain \& Soulé (1981), o fator psíquico continua sendo apontado como um fator desencadeante que vem "por assim dizer, poluir a pureza do fenômeno fundamental, que é de ordem biológica” (p. 241).

\section{Cultura e Educação em Asma}

As crianças que participaram deste estudo têm asma desde bebês, fato que fez com que a cultura médicohospitalar passasse a fazer parte de suas vidas desde muito cedo. Através do discurso de suas mães, vimos a inserção destas em uma cultura médica que lhes serve de suporte para o cuidado dos filhos. O que contam, no entanto, gira em torno mais dos cuidados necessários para evitar as crises do que de um conhecimento a respeito da patologia em si. Isso pode dever-se ao fato de que, no Programa, há uma ênfase bastante grande no controle do ambiente para evitar as crises de asma.

Foi possível identificar, também, as mudanças que ocorreram nas crenças destas mães em relação à doença devido ao que aprenderam com os médicos. "primeiro o médico disse que era bronquiolite, aí eu tratei, tratei, tratei, tratei, daí depois ele disse que não, que era bronquite, aí agora que eles disseram que não, que é asma, que tudo é a mesma coisa, que para mim asma era pior que bronquite e eles dizem ali que não, que tudo é a mesma coisa" ... "Ele sempre teve o peitinho chiando, mas eu achava que era normal e com sete meses ele teve a crise de asma. O médico disse que ele teve uma crise de asma. Do ano passado para cá com o grupo de asma, eu aprendi mais como é que a crise dava nele" ... "Na época eu não achei que tivesse culpa, foi de consultar e conversando com as pessoas que eu pensei que poderia ter culpa, eu estava bem tranqüila que a causa era o clima, eu não sei da onde veio isto, se foi uma vez que eu fui numa pediatra e ela acertou um broncodilatador do Rafael, aí ele ficou um tempo sem ter crise, aí ele voltou a ter crise e ela teria me dito que isto era fundo emocional, que ele poderia ter se estressado com alguma coisa". A mãe de Rafael, por exemplo, alterna, durante a entrevista, várias hipóteses a respeito da doença do filho. Esquematicamente: água do parto $\rightarrow$ fundo emocional/morte do pai $\rightarrow$ fundo emocional/culpa da mãe $\rightarrow$ hereditariedade $\rightarrow$ clima $\rightarrow$ fundo emocional/culpa da mãe. A partir dos elementos que a cultura médico-hospitalar lhe fornece, ela modifica as explicações sobre a doença do filho, mas isso é regulado, também, pela maneira como se coloca em relação à maternidade, isto é, sentindo-se mais ou menos implicada com o que se passa com Rafael. Isto reforça a idéia de que o que se apreende da cultura é modulado pela posição subjetiva.

Ao examinar os esquemas culturais que os pacientes utilizam para interpretar e representar a experiência de sua doença, Garro (1994) encontrou a dicotomia mente e corpo 
como o modelo cultural que embasava e dava coerência à diversidade de relatos individuais. No discurso das mães de Larissa, Rafael e Vítor, também, foi possível situar esta questão na alternância que fazem a respeito dos desencadeantes da asma dos filhos, ora a partir de um "fundo emocional"'(mente) ora em função de um problema ambiental (corpo): "o médico disse que ela é hiper alérgica" ... "ele (médico) me disse que tem asma que é fundo emocional, tem asma que é devido ao clima A hereditariedade também é trazida pelas mães nas explicações que formulam para a doença dos filhos. "Eu tive uma crise quando ele nasceu, a minha irmã tem, a minha falecida tia também tinha, a minha sogra tem, meu marido tinha ...".

A função do Programa de Educação em Asma também foi apontada pelas mães como uma referência para elas e seus filhos de como lidar com a doença. A mãe de Larissa, por exemplo, enfatiza a possibilidade de Larissa conviver melhor com as limitações impostas por sua doença. "Não, eu senti que ela, que coisas que ela fazia antes agora ela não faz, por exemplo, os bichinhos de pelúcia ela procura não brincar" e a mãe de Vítor conta que, agora, "ele já sabe os seus sintomas". No brincar das crianças, como já discutimos anteriormente, vê-se com clareza a presença de elementos aprendidos nas aulas. "Vamos lá no consultório (pega réplicas de brônquios usadas nas aulas) Olha o que eu achei, mãe, uma coisa, os brônquios, eles têm muito catarro, muito, muito, muito catarro, esse aqui está igual ao cano, tá trancado ...". Esse é um exemplo claro de como a cultura hospitalar passa a fazer parte da vida destas crianças, sendo assim incorporados muitos elementos da linguagem médica ao seu discurso e ao seu brincar. Muitas vezes, no entanto, o que se vê é uma repetição, sem que haja uma compreensão maior do que foi aprendido. Isso pode ser ilustrado por uma conversa com Vítor: P: "E daí, o que que acontece quando tu ficas com crise? V- Os brônquios fecham. P- Os brônquios fecham e o que mais? $\mathrm{V}-$... eu tenho que vim pra cá (refere-se ao hospital) P- tem que vir pra cá pro hospital ... e o que acontece quando tu chega aqui? V - eu faço nebulização". Como pode ser visto, Vítor usa o termo brônquios que aprendeu nas aulas, mas não vai muito além disto. No decorrer da conversa apenas descreve o que se passa quando tem as crises. Isso aponta reprodução, mais do que a compreensão do que lhe é ensinado.

Ao pensar-se a inserção de tais elementos da cultura hospitalar no discurso, tanto das mães quanto das crianças, não se deve perder de vista o fato de que estes conteúdos inserem-se, também, através do ensino formal, nas aulas do Programa. Tendo isso em vista, é importante refletir sobre um tipo de educação que se propõe a transmitir ao sujeito e sua família conhecimentos, justamente, a respeito daquilo que lhes faz padecer. As peculiaridades que fazem parte de um Programa de Educação para Asma situam-se no fato de que se trata, em alguma medida, da educação a respeito do próprio sujeito, isso tendo como pressuposto que a asma "participa de uma certa constituição do sujeito, de um certo modo de relação com o mundo" (Bélot-Fourcade, 1998, p. 38). Sabe-se, por outro lado, que todo processo de educação produz efeitos na constituição do sujeito que vão além da pura transmissão de informações. Vale a pena lembrarmos aqui as palavras de Millot (1987): “Quando o pedagogo imagina estar se dirigindo ao Eu da criança, o que está atingindo, sem saber, é seu Inconsciente; e isso não ocorre pelo que crê comunicar-lhe, mas pelo que passa de seu próprio Inconsciente através de suas palavras” (p. 150). São esses efeitos sobre o sujeito que se deve examinar. Mais do que uma preocupação a respeito daquilo que a criança aprende ou não aprende para o controle de sua asma, deve-se analisar a maneira como ela toma isso que aprende e o que isso pode produzir em sua subjetividade.

$\mathrm{O}$ fato de que mães e crianças reproduzem o que lhes é ensinado não é suficiente para que se possa acreditar que o Programa teve êxito. Deve-se ir além, uma vez que o que chama atenção é o pouco espaço para algo singular, em relação a este conhecimento. O que pode constituir-se em uma tarefa eminentemente educativa é, justamente, o fato de que o sujeito possa, a partir de alguns elementos, reconstruí-los trabalhosamente, até que possa reconhecerse nesse conhecimento que passa a ser marcado por um estilo próprio. Essa parece ser a regulação necessária ao que vem sendo proposto pelo Programa a estas crianças e sua mães: colocar a informação de tal forma que exista um espaço para que o sujeito construa algo próprio em relação ao conhecimento. Como foi visto, a cultura hospitalar tem uma função importante, uma vez que estabelece uma espaço para além da relação mãe e filho, produzindo aí em corte. O que falta, no entanto, é que esse corte possa ser menos pleno de significações, deixando espaços para que algo do sujeito possa surgir.

\section{Conclusão}

A análise e discussão dos dados aqui apresentados evidenciou a importância de investigar-se a perspectiva da criança asmática em relação às informações que recebe a respeito de sua doença. Observou-se que a doença faz parte da vida destas crianças como um todo e que, portanto, as intervenções em relação a elas não podemse restringir a termos médicos. É necessário que elas possam ter um espaço para comunicar suas vivências em relação à doença, de modo a que se possa monitorar a maneira como estão significando as informações que lhe 
são fornecidas. Percebeu-se que o Programa de Educação para Asma tem um caráter extremamente informativo e que as crianças, embora apreendam muito destas informações, não encontram vias para manifestar suas inquietações em relação ao que lhes acontece. A criança não fala por si, mas é convidada a compor um diálogo já estabelecido a partir de um saber médico. Aliado ao tipo de posição subjetiva em que essas crianças se encontram, o que aparece são significações que reproduzem diretamente este saber.

O conhecimento, por parte da equipe técnica, da maneira como as crianças que participaram deste estudo construíram suas narrativas pode ser útil para que possam ser revistos e planejados os tipos de intervenção que se tem no Programa. O tipo de representação, em que os objetos aparecem muito colados a suas funções, por exemplo, indica que se deve possibilitar à estas crianças atividades lúdicas que propiciem a simbolização. Desta forma, mais do que ensinar como utilizar os remédios ou como fazer o controle do ambiente, é fundamental que estas crianças possam manipular de forma lúdica estes objetos, o que possibilitaria uma ampliação das possibilidades simbólicas.

A construção das narrativas do brincar, neste sentido, pode configurar-se como um instrumento interessante para os profissionais que trabalham com estas crianças. Além de permitir que as crianças organizem sua experiência de forma narrativa e elaborem através do brincar os conteúdos ali presentes, a narrativa serve como uma ferramenta para que o profissional possa conhecer a maneira como seu paciente vem significando aquilo que the acontece.

Como salienta Ricouer (1983/1994), "compreender uma história é compreender ao mesmo tempo a linguagem do "fazer" e a tradição cultural da qual procede a tipologia das intrigas" (p. 91). Desta forma, além de ter acesso ao "fazer" destas crianças, é possível também refletir a respeito da posição que determinado tipo de cultura médico-hospitalar ocupa na vida destas. Isso poderia desequilibrar alguns saberes já estabelecidos. É certo que a partir de outras narrativas poder-se-ia ter acesso a outras informações importantes em relação a estas crianças.

Não se pode perder de vista, também, o fato de que a leitura e a interpretação de uma narrativa será sempre um reflexo da ótica de seu espectador. Como salienta Todorov (1973), “o processo de leitura não será, jamais, sem conseqüências: dois leitores de um livro não são jamais idênticos" (p. 17). Desta forma, as interpretações das narrativas presentes neste estudo são marcadas por um olhar específico, que fica evidente a partir dos recortes feitos e do referencial utilizado para analisar os casos. Uma descrição objetiva, no entanto, não seria suficiente para analisar as significações das crianças, que é um dos objetivos deste estudo. "Os fatos da significação, que constituem o objeto da interpretação, não se adequam à 'descrição', se se atribui a este termo o sentido de absoluto e de objetivo" (Todorov, 1973, p. 17). Avançou-se para além da descrição dos fatos, portanto, mesmo levando-se em conta que outras interpretações poderiam ser possíveis e que aspectos relevantes podem ter sido esquecidos. A leitura mantevese, no entanto, constantemente referida ao espaço do texto que foi depreendido através do brincar das crianças, com o intuito de preservar, tanto quanto possível, o material fornecido pelos autores das histórias. A interpretação das narrativas situou-se, então, na "intersecção entre o mundo do texto e o mundo do ouvinte ou do leitor" (Ricouer, 1983/1994, p. 110).

Possibilitar às crianças que construam narrativas no contexto da cultura hospitalar é permitir, também, que elas contem algo sobre a história de suas vidas. Novamente, as palavras de Ricoeur (1983/1994) fornecem importantes considerações a este respeito.

... a história acontece a alguém antes que alguém a narre. $\mathrm{O}$ emaranhamento aparece antes como a "pré-história" da história narrada da qual o começo permanece escolhido pelo narrador. Essa "pré-história" da história é a que a vincula a um todo mais vasto e dá-lhe um "pano de fundo". Esse pano de fundo é feito pela "imbricação viva" de todas as histórias vividas umas nas outras. É preciso pois que as histórias narradas "emerjam" (auftauchen) desse pano de fundo. Com essa emergência, o sujeito implicado emerge também. (pp. 115-116)

Um aspecto fundamental deste estudo é a necessidade de que se constitua um momento em que as crianças disponham de um espaço para construir histórias, na perspectiva de que, podendo contá-las, possam cada vez mais emergir como sujeitos de sua história.

\section{Referências}

Adam, J-M. (1985). Le texte narratif. Paris: Nathan.

Barthes, R. (1977). Analyse structurale des recits. Paris: Editions du Seuil.

Bélot-Fourcade, P. (1998). Considerações pneumáticas sobre "A Grande Atmosfera". Em A. B. Teixeira (Org.), O sujeito, o real do corpo e o casal parental (pp. 38-50). Salvador: Ágalma.

Bennet, D. S. (1994). Depression among children with chronic medical problems: A meta-analysis. Special Issue: Chronic illness. Journal of Pediatric Psychology, 19, 149-169.

Benson, M. (1993). The structure of four- and five-year-olds' narratives in pretend play and storytelling. First-language, 13, 203-223.

Bruner, J. (1987). Life as narrative. Social research, 54, 11-32.

Bruner, J. (1997). Atos de significação (S. Costa, Trad.). Porto Alegre: Artes Médicas. (Original publicado em 1990) 
Buchsbaum, H. \& Emde, R. (1990). Play narratives in 36-month-old children: Early moral development and family relationships. Psychoanalytic Study of the Child, 45, 129-155.

Buchsbaum, H., Toth, S., Clyman, R. \& Cicchetti,D. (1992). The use of a narrative story stem technique with maltreated children: Implications for theory and practice. Special Issue: Developmental approaches to prevention and intervention. Development and Psychopathology, 4, 603-625.

De Conti, L. \& Sperb, T. M. (2001). O brinquedo de pré-escolares: Um espaço de ressignificação cultural. Psicologia: Teoria e Pequisa, 17, 59-67.

Garro, L. (1994). Narrative representation of chronic illness experience: Cultural models of illness, mind, and body in stories concerning the temporomandibular joint (TMJ). Social Science and Medicine,38, 775-778.

Goodman, N. (1981). Twisted tales; or, story, study and sinphony. Em W. J. T. Michel (Org.), On narrative (pp. 99-115). Chicago: University of Chicago Press.

Hemphill, L., Feldman, H., Camp, L. \& Griffin, T. (1994). Developmental changes in narrative and non-narrative discourse in children with and without brain injury. Journal of Communication Disorders, 27, 107-133.

Howell, J. H., Flaim, T. \& Lum Lung, C. (1992). Patient education. Pediatric Clinics of North America, 39, 1343-1361.

Kreisler, L., Fain, M. \& Soulé, M. (1981). A criança e seu corpo: Psicossomática da primeira infância. Rio de Janeiro: Zahar. (Original publicado em 1978)

Marty, P. (1993). A psicossomática do adulto. Porto Alegre: Artes Médicas. (Original publicado em 1990)

Mello, C. O., Faschel, J. \& Sperb, T. M. (1997). A interação social na brincadeira de faz-de-conta: Uma análise da dimensão metacomunicativa. Psicologia: Teoria e Pesquisa, 13, 119-130.

Mello, C. O., Goulart, C. M. T., Ew, R. A. \& Sperb, T. M. (1999). Brincar no hospital: Assunto para discutir e praticar. Psicologia: Teoria e Pesquisa., 15, 6574.

Millot, C. (1987). Freud antipedagogo. Rio de Janeiro: Jorge Zahar. Oliveira, H. (1993). A enfermidade sob o olhar da criança hospitalizada. Caderno de Saúde Pública, 9, 326-332.
Padur, J. S., Rapoff, M., Houston, B. K., Barnard, M., Danovsky, M., Olson, N. Y., Moore, W. V., Vats, T. S. \& Liberman, B. (1995). Psychosocial adjustment and the role of functional status for children with asthma. Journal of Asthma, 32, 345-353.

Quinn, C. (1988). Children's asthma: New approaches, new understandings. Annals of Allergy, 60, 283-292.

Ricoeur, P. (1994). Tempo e Narrativa (Tomo I) (C. M. Cesar, Trad.). São Paulo: Papirus. (Original publicado em 1983)

Shute, R. \& Paton, D. (1990). Childhood ilness: The children as helper. Em H. Foot, M. Morgan \& R. Shute (Orgs.), Children helping children (pp. 327-350). New York: Hohn Wiley \& Sons.

Snadden, D. \& Brown, J. B. (1992). The experience of asthma. Social Science and Medicine, 34, 1351-1361.

Todorov, T. (1971). Poética da prosa. Lisboa: Edições 70.

Todorov, T. (1973). Qu'est-ce que le structuralisme?: Poétique. Paris: Édition du Seuil.

Vieira, A. (1997). O brinquedo simbólico como uma narrativa. Dissertação de Mestrado não-publicada, Curso de Pós-graduação em Psicologia do Desenvolvimento, Universidade Federal do Rio Grande do Sul. Porto Alegre, RS.

Vieira, A. G. \& Sperb, T. M. (1998). O brinquedo simbólico como uma narrativa. Psicologia: Reflexão e Crítica, 11, 233-252.

Yin, R. K. (2001). Estudo de caso: Planejamento e método (D. Grassi, Trad.). Porto Alegre: Bookman. (Original publicado em 1994)

Sobre as autoras

Cláudia Maria Teixeira Goulart é Psicóloga, Especialista em Teoria e Clínica Psicanalítica e Psicológica pela Universidade Federal do Rio Grande do Sul, Mestre em Psicologia do Desenvolvimento pela Universidade Federal do Rio Grande do Sul, Psicóloga do Centro Interdisciplinar e Oficinas Terapêuticas MOSAICO. É Professora do Centro Universitário FEEVALE.

Tania Mara Sperb é Psicóloga, Mestre e PhD em Psicologia do Desenvolvimento pelo Instituto de Educação da Universidade de Londres. É Professora adjunto IV do Instituto de Psicologia da Universidade Federal do Rio Grande do Sul. 